\title{
Using Minecraft to engage children with science at public events
}

\author{
Laura Hobbs*, Carly Stevens, Jackie Hartley, Mark Ashby, Isobel Lea, \\ Lauren Bowden, Jordan Bibby, Benjamin Jackson, Rhian McLaughlin and \\ Thomas Burke - Lancaster University, UK
}

\begin{abstract}
Engagement with science and scientific skills is an important aspect of children's ability to navigate the world around them, but engagement with science is low in comparison with other subjects. The Lancaster University outreach project Science Hunters takes a novel approach to engaging children with environmental science research through a constructivist pedagogical approach using the popular computer game Minecraft. While Minecraft is extensively used in formal education settings, few data are available on its use in public engagement with scientific research, and the relationship between children's and adults' attitudes to science and computer games are complex. Through motivational surveys conducted as part of the project evaluation, we analysed feedback from participants who attended sessions as part of a programme at public events, to explore the basic demographics of children attending our events, and whether it is the prospect of learning about science, or the opportunity to play Minecraft that leads them to choose our activity. We also present evaluation of general feedback from participants at public events over four years to give a broader view of participants' response to the activities.
\end{abstract}

Keywords: science communication, informal learning, Minecraft, environmental science

\section{Key messages}

- General feedback is highly positive; children are having fun and engaging with the scientific research and learning presented.

- Minecraft is a driver behind the decision to attend the activity; while many participants are also interested in science, more choose this activity because Minecraft, rather than science, is involved.

- The Science Hunters approach is effective at attracting and engaging people to engage with scientific research and is transferable to other fields.

\section{Introduction and background}

As part of their education, children need to develop a range of skills and knowledge that enables them to understand scientific and technological aspects of the world around them, including evidence-based reasoning, inquiry-based skills and understanding the nature of science and how scientific knowledge is developed ('scientific literacy') 
(Harlen and Qualter, 2018). This is important not only for future scientists, but for everyone, as the basic principles of scientific understanding are extremely valuable tools in navigating the world and everyday life, and a scientifically literate population is beneficial for society as a whole (see, for example, Czerski, 2016; House of Commons Science and Technology Committee, 2017; Harlen and Qualter, 2018).

However, there is abundant evidence that, in comparison with other school subjects, science is failing to engage children and young people (for example, Archer et al., 2012 and references therein). For example, while younger children commonly enjoy science (Murphy and Beggs, 2005; Kerr and Murphy, 2012), and many adults think science is important in everyday life and that young people's interest in science is essential for future prosperity (Castell et al., 2014), children's interest in science begins to decline at around age 10 (Murphy and Beggs, 2005), and there is a substantial body of evidence indicating that their overall interest in science is formed by age 14 (Archer et al., 2012 and references therein). This decline is less apparent when children are involved in practical, investigative activities (Murphy et al., 2004), and teachers suggest that making science more relevant to pupils' experience is the best way to improve science teaching and learning (Murphy and Beggs, 2005). Cultural biases, such as perceptions of scientists as 'brainy', also lead to people feeling that science is not 'for them' outside of formal education settings (for example, Archer et al., 2013; House of Commons Science and Technology Committee, 2017). Therefore, initiatives that encourage young people to engage with science, and complement science learning in formal education, are vital for increasing our science capital (sciencerelated knowledge, experiences, attitudes and resources; Archer et al., 2012) (House of Commons Science and Technology Committee, 2017).

Science Hunters was initiated in 2014 as a small project aiming to use the computer game Minecraft to communicate scientific concepts and inspire interest in, and enthusiasm for, science in children. This approach draws on the knowledge of the increased efficacy of learning when it is fun (Lepper and Cordova, 1992) and the long history of using computer games to enhance education (for example, Betz, 1995; Amory et al., 1999; Jayakanthan, 2002; Hobbs et al., 2019). Now in its fifth year, the project has grown substantially and currently engages around 6,000 children each academic year. Science Hunters activities are open to children of all ages and include visits to schools, Minecraft clubs for children in specific groups (such as children who are in care, or who have autism) and attendance at public events and festivals, along with other sub-projects such as production of home packs and online resources to enable families to undertake activities at home.

Minecraft is an extremely popular game, particularly with children; Lane and Yi (2017) describe it as one of the most important, and widely used, computer games of the current generation. Minecraft is a construction-based, open-world game in which players are able to create an infinite variety of structures by utilizing blocks with a wide range of appearances and properties. The Minecraft worlds within which each player operates emulate ecologically realistic environments and physical processes, making the game an ideal teaching tool for increasing scientific literacy among children (Lane and Yi, 2017; Short, 2012; Hobbs et al., 2018a). Science Hunters uses an educational version of Minecraft set within 'creative' mode to ensure a safe play environment and unlimited access to building blocks.

Minecraft is used extensively in educational contexts, from literacy (for example, Litcraft (Lancaster University, n.d.)) to geography (for example, Short, 2012) and chemistry (for example, Molcraft (Mojang, 2019a)). A Minecraft educator online community provides resources and support via the Minecraft Education Edition website (Mojang, 
2019b). The simplicity and relative affordability of the game make it a viable option for classroom use for both students and teachers. Its accessibility facilitates active construction of knowledge, and children can collaborate and engage with questions within its interactive environment (Nebel et al., 2016). Detailed accounts of Minecraft's features and its use in a variety of formal educational settings and research contexts are given in Nebel et al. (2016) and Lane and Yi (2017), and include its application to arts, computing, physics, chemistry, geology, storytelling and social skills education. However, while there is a growing body of work on the use of Minecraft in education and learning research (Nebel et al., 2016 and references therein), there is relatively limited information available about its use in facilitating informal science learning and public engagement with science more broadly.

While children in schools are selected for participation in Science Hunters activities by their teachers, children attending sessions at public events do so by choice, with the agreement of their parents/carers. Therefore, in order to explore the appeal of the project's activities, we investigate the efficacy of the project's use of Minecraft to engage children with science and research at public events as part of our project evaluation. In this paper, we evaluate general feedback from public events to assess attendees' experience of the sessions, and where Science Hunters sessions are part of a larger programme of activities, we look at what motivates people to choose our particular activity. Who is choosing to attend our sessions; for example, do they appeal to a particular age range? Are the sessions only appealing to people who are strongly interested in science or Minecraft, or to a broader audience? Minecraft is an extremely popular game (Lane and $\mathrm{Yi}_{1}$ 2017), yet many adults struggle with the amount of time their children spend on computer games (Nebel et al., 2016), and children and adults often enjoy and see the value of science (for example, Murphy and Beggs, 2005; Castell et al., 2014), but engagement with and attitudes towards science are not always positive (for example, Archer et al., 2013; House of Commons Science and Technology Committee, 2017). Therefore, which element most drives people to attend, the science or the Minecraft?

\section{Methods}

\section{Project approach and delivery}

As a Widening Participation project, Science Hunters particularly aims to reach children who face one or more barriers to accessing higher education, such as disability, low family income, being of the first generation in their family to attend university, being of Black, Asian and Minority Ethnic background, or being in care/a care leaver (Lancaster University, 2019). While it is more difficult to target these groups, and to monitor uptake, at public events than it is in schools and at Minecraft clubs, where attendees are known to the school or project, activities are always designed to be relaxed, informal and accessible to all, in order to enable as wide a range of people as possible to participate (Hobbs et al., 2019). For example, we readily adapt delivery and the Minecraft challenges set to cater for a range of ages, abilities and needs. We do not charge for our activities and ensure that there is no pressure on children to participate, complete their challenges or execute them in a particular way. We choose to take our activities to community-based venues such as libraries, which are familiar and appropriate to family-based audiences, or to family-oriented festivals, so that the educational aspects of the activity are non-intrusive and the research involved is accessible and inclusive (ibid.).

Research areas that have been covered include food security, volcanology, animal adaptations, parasite ecology, plant biology, insect ecology, coral reef ecosystems, 
flood management and bioluminescence. Pedagogically, we employ a learner-centred constructivist approach (Brooks and Brooks, 2001; Rovai, 2004), using anchored instruction (Cognition and Technology Group at Vanderbilt, 1990) and constructionism (Papert and Harel, 1991), which is facilitated by the accessibility of Minecraft and its capability to support transformational play (changing their play environment; Barab et al., 2012) by allowing interaction with, and modification of, the virtual environment (for example, development of farms) and creation of almost any structure using blocks (Nebel et al., 2016). Through this approach, we encourage inquiry-based learning by supporting children to develop their understanding through their own ideas and efforts alongside collaboration with others, an approach endorsed by a growing body of empirical evidence and professional knowledge (for example, Loyens and Gijbels, 2008; Harlen and Qualter, 2018). We first introduce a scientific topic via interactive discussions, hands-on activities and demonstrations, and then set children a related problem to solve in Minecraft. The approach that children choose to solve this problem is guided by their own imagination and the aspect of the topic they find most interesting, with guidance from session staff (see Figure 1). This focus on the students directing their own learning and solving problems through the use of Minecraft, with a clear emphasis on constructing understanding and meaning from the information they have been given, was chosen as it ensures that children can find and maintain interest in, and understanding of, scientific topics and feel a sense of ownership and that science is 'for them', while consolidating their learning (Hobbs et al., 2018a). As an example, a 'volcanoes' session might include (depending on the ages, abilities and needs of the group attending) an interactive discussion and demonstrations about volcanic hazards and hands-on activities introducing different types of volcanic rocks. This would be followed by a related challenge, which could be to build a volcano, to create a particular rock type using interactions in Minecraft that are analogous to processes occurring in the real world, or to build features in order to manage a volcanic hazard (see Figure 2 and Figure 3). Detailed descriptions of session structures can be found in Hobbs et al. (2018a, 2018b, 2019).

\section{Figure 1: Children participating in a Science Hunters session, building parasites at Campus in the City (2018), with support from Science Hunters volunteer Amber Drinkwater}

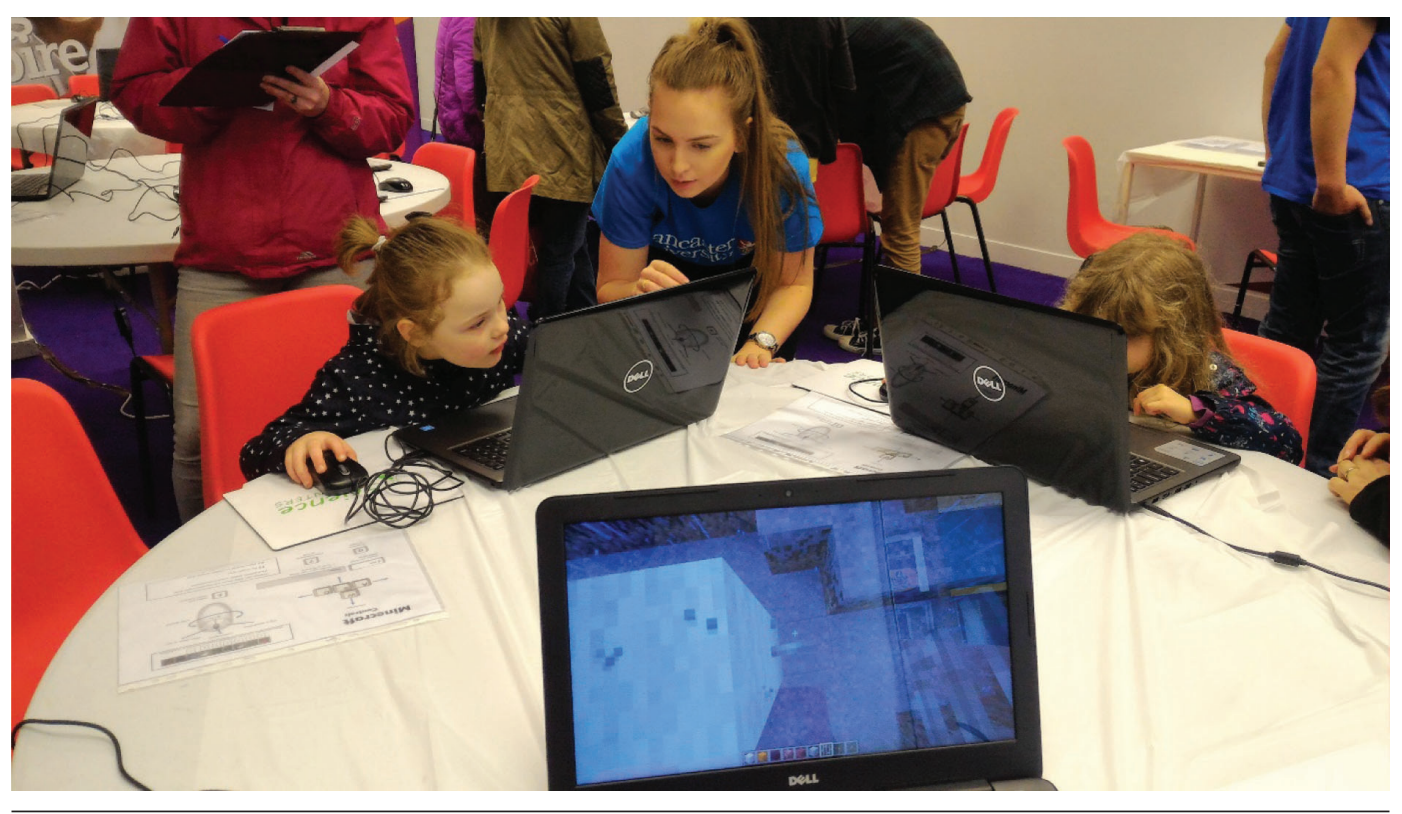


Figure 2: A 5-year-old child explores lava and water interactions in Minecraft at a Science Hunters public event

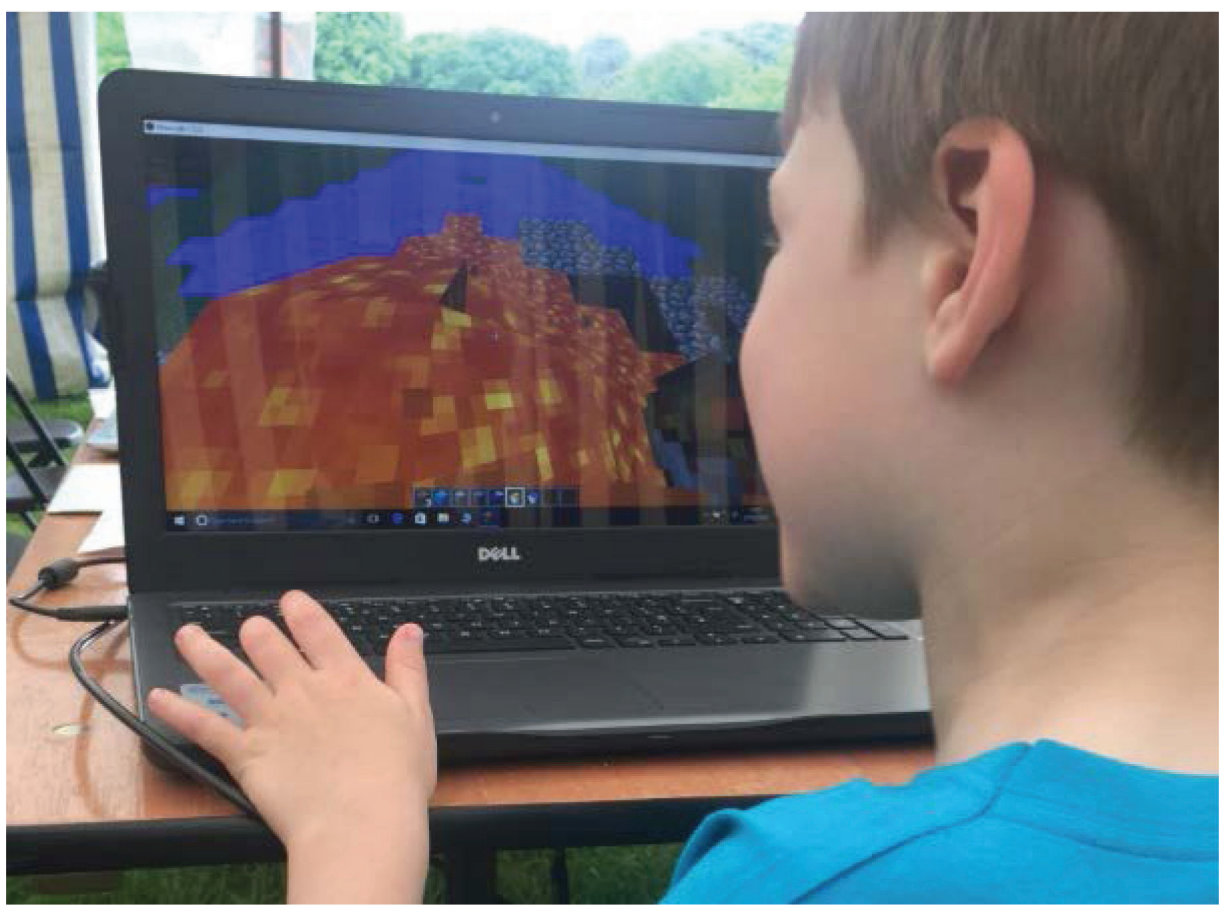

Figure 3: Lava (orange) from a volcano built during a Science Hunters Minecraft club session is prevented from reaching other constructions using walls (black) and water (blue) to impede its flow

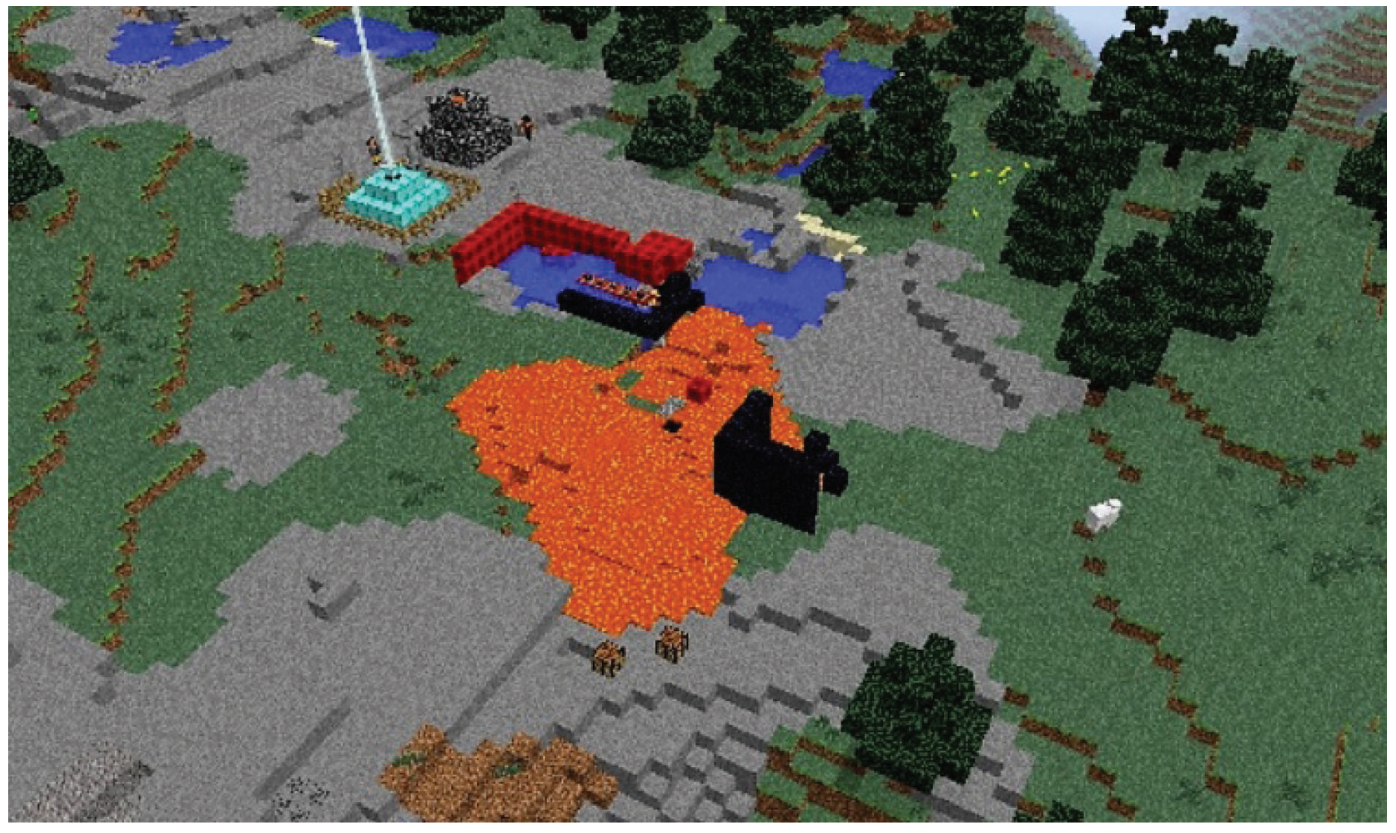

\section{Evaluation data collection and analysis}

The evaluation data analysed here were gathered from a range of public events between 2015 and 2018, as detailed in Table 1. These events were both small (attended 
by $\leq 50$ children) and large (attended by $\geq 100$ children). It should be noted that at the larger events, due to limitations imposed by physical space and numbers of computers available, the largest number of children involved at any one time was under fifty and was most commonly ten to twenty, so that participant numbers at any one time were broadly consistent.

Table 1: Public events at which evaluation data used in this analysis were collected for Science Hunters

\begin{tabular}{|c|c|c|c|c|c|c|}
\hline Year & Location & $\begin{array}{l}\text { Number } \\
\text { of } \\
\text { children }\end{array}$ & $\begin{array}{l}\text { Part of } \\
\text { a larger } \\
\text { event? }\end{array}$ & $\begin{array}{l}\text { If yes, a } \\
\text { science } \\
\text { event? }\end{array}$ & $\begin{array}{l}\text { General or } \\
\text { motivational } \\
\text { evaluation } \\
\text { data used }\end{array}$ & $\begin{array}{l}\text { Number of other } \\
\text { activities on offer } \\
\text { and total event } \\
\text { attendees }\end{array}$ \\
\hline 2015 & $\begin{array}{l}\text { Lancaster Central } \\
\text { Library, Lancaster, } \\
\text { Lancashire }\end{array}$ & 28 & No & $N / A$ & General & $\begin{array}{l}0 \text { other activities, } \\
28 \text { total attendees }\end{array}$ \\
\hline 2016 & $\begin{array}{l}\text { Lancaster Central } \\
\text { Library, Lancaster, } \\
\text { Lancashire }\end{array}$ & 25 & No & $N / A$ & General & $\begin{array}{l}0 \text { other activities, } \\
25 \text { total attendees }\end{array}$ \\
\hline 2016 & $\begin{array}{l}\text { Heron Corn } \\
\text { Mill, Beetham, } \\
\text { Cumbria }\end{array}$ & 44 & No & $N / A$ & General & $\begin{array}{l}0 \text { other activities, } \\
44 \text { total attendees }\end{array}$ \\
\hline 2017 & $\begin{array}{l}\text { Lancaster } \\
\text { University } \\
\text { Community } \\
\text { Day, Lancaster, } \\
\text { Lancashire }\end{array}$ & 212 & Yes & No & Motivational & $\begin{array}{l}80 \text { other activities, } \\
2,000 \text { total } \\
\text { attendees }\end{array}$ \\
\hline 2017 & $\begin{array}{l}\text { Lancashire } \\
\text { Science Festival, } \\
\text { Preston, } \\
\text { Lancashire }\end{array}$ & 194 & Yes & Yes & Motivational & $\begin{array}{l}8 \text { other workshops/ } \\
\text { approx. } 200 \text { other } \\
\text { activities available. } \\
\text { Total attendance } \\
\text { 13,000 across } \\
\text { three-day festival }\end{array}$ \\
\hline 2018 & $\begin{array}{l}\text { Lakeland } \\
\text { Wildlife Oasis, } \\
\text { Milnthorpe, } \\
\text { Cumbria }\end{array}$ & 22 & No & $N / A$ & $\begin{array}{l}\text { Motivational } \\
\text { General }\end{array}$ & $\begin{array}{l}1 \text { other activity } \\
\text { available, } 28 \text { total } \\
\text { attendees }\end{array}$ \\
\hline 2018 & $\begin{array}{l}\text { Campus in the } \\
\text { City, Lancaster, } \\
\text { Lancashire }\end{array}$ & 190 & Yes & No & General & $\begin{array}{l}0 \text { other activities } \\
\text { available, } 190 \text { total } \\
\text { attendees }\end{array}$ \\
\hline 2018 & $\begin{array}{l}\text { Geronimo } \\
\text { Children's } \\
\text { Festival, Arley } \\
\text { Hall, Cheshire }\end{array}$ & 554 & Yes & No & $\begin{array}{l}\text { Motivational } \\
\text { General }\end{array}$ & $\begin{array}{l}\text { Approx. } 130 \text { other } \\
\text { activities, } 20,000 \\
\text { total attendees } \\
\text { (estimated) }\end{array}$ \\
\hline 2018 & $\begin{array}{l}\text { Lancashire } \\
\text { Science Festival, } \\
\text { Preston, } \\
\text { Lancashire }\end{array}$ & 403 & Yes & Yes & General & $\begin{array}{l}7 \text { other workshops/ } \\
\text { approx. } 200 \text { other } \\
\text { activities available, } \\
13,000 \text { attendees } \\
\text { across three-day } \\
\text { festival }\end{array}$ \\
\hline
\end{tabular}

Note: Participant numbers refer only to the number of children attending the Science Hunters activity. General evaluation data refer to feedback about the activity; motivational evaluation data concern what prompted people to choose the Science Hunters activity out of all those on offer at the event. 
At five of these events, other activities were available. For context:

- At Lancaster Community Day 2017, these included activities based on art and music, and science, technology, engineering and maths showcasing and experiments, sport and wellness, play, food, and community and emergency services. More information is available at www.lancaster.ac.uk/events/ community-day/.

- At Lancashire Science Festival 2017 and 2018, a large programme of sciencerelated events was available, including workshops (of which the Science Hunters activity was one), stage shows and demos, hands-on drop-in activities, and activities with community and emergency services. More information is available at https://lancashiresciencefestival.co.uk/archive/. It should be noted that in both years, attendance figures for Science Hunters workshops were capped by availability of facilities, with attendance via advance booking only. All were full to capacity.

- At Lakeland Wildlife Oasis in 2018, the wildlife centre (a small, all-weather zoo) itself was also open to visitors. There was a total of 88 visitors to the zoo, of whom 28 were children, on the day of the event. The zoo is a fee-charging visitor attraction; entry to the Science Hunters activity only was free of charge.

- At Geronimo Children's Festival in 2018, a wide programme of children's activities was available across three days. These included stage shows, music, circus and theatre workshops, sport and well-being activities, children's entertainers, and a funfair.

General feedback was collected during small events at which there were no alternative activities on offer between 2015 and 2016 (Lancaster Library in 2015 and 2016, and Heron Corn Mill in 2016) through 'word wall' feedback by which adults and children could leave their comments. This method was chosen as an anonymous, fun method of collecting feedback that did not intrude on engagement with the activity as it could be completed outside active participation in the session, for example at the point of leaving.

During 2018, general feedback for Science Hunters sessions was collected using feedback cards inviting 'smiley face' negative/neutral/positive feedback responses and comments at Campus in the City, Lakeland Wildlife Oasis, Geronimo Children's Festival and Lancashire Science Festival. This method was developed as the project progressed and expanded over several years, with changing evaluation needs, and moved from delivering exclusively at small, localized events to participating in larger multi-activity events with wider reach. Using rating scales such as the smiley face scheme allows efficient assessment of attendees' opinions of the activity as a quantifiable measure of success, and is more accessible to children with lower levels of literacy than a word wall. Figure 4 shows an example of a word wall; Figure 5 shows a smiley face feedback card.

The contents of all comments given were grouped into the following categories: (1) indication of fun/enjoyment; (2) activity location; (3) reference to the science topic; (4) educational elements; (5) staff and atmosphere; (6) mention of Minecraft; (7) excitement; (8) experiencing technology; and (9) negative comments. Responses given via smiley faces have been translated into positive, neutral and negative feedback. Evaluation information collected centrally by main event organizers is not included here. 
Figure 4: A portion of the 'word wall' feedback left at Lancaster Library in 2015 (some identifying details have been redacted for privacy)

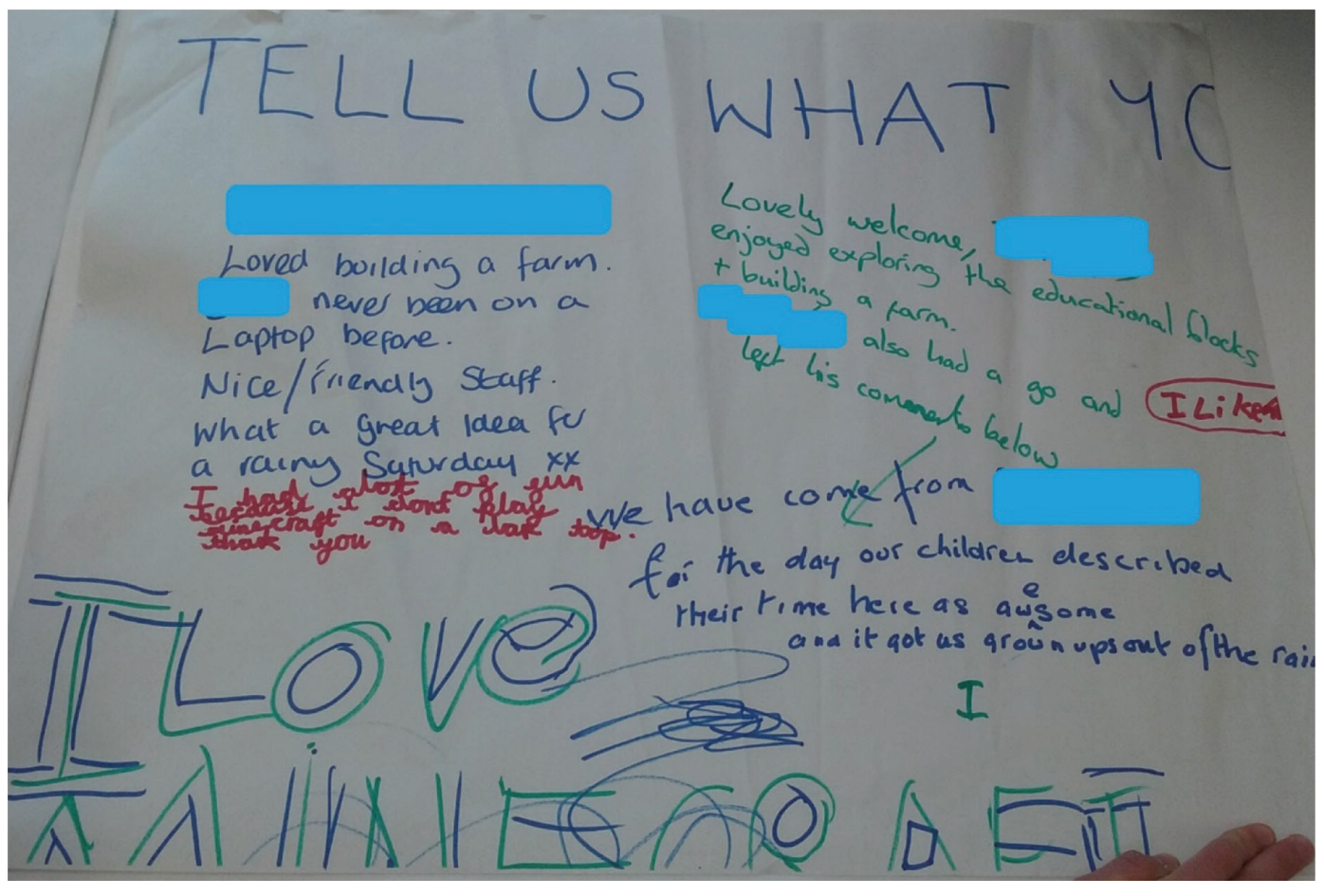

Figure 5: An example of a feedback card returned at Geronimo Children's Festival in 2018

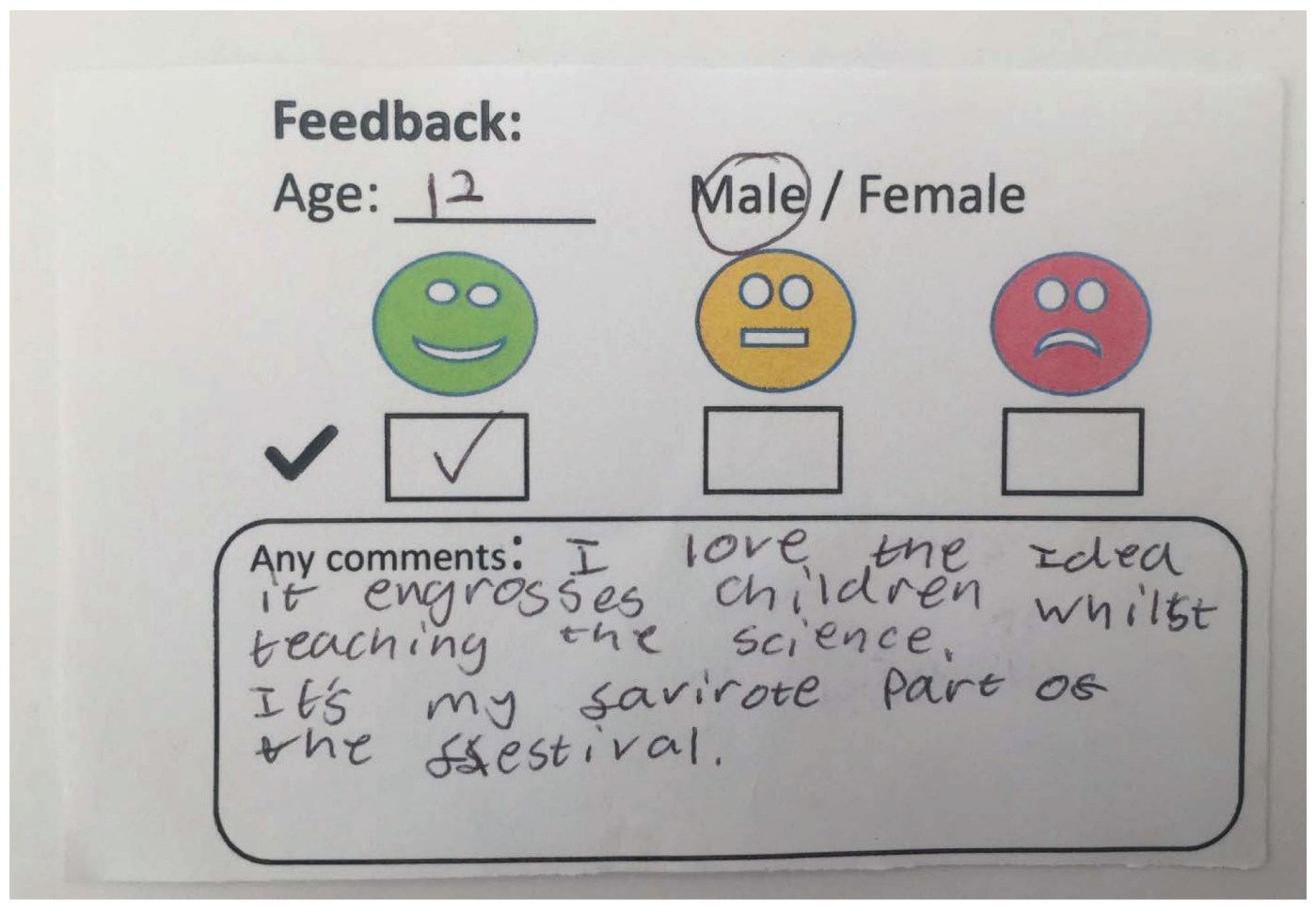


As the reasons behind the project's successful attraction of participants at public events (Hobbs et al., 2019) cannot intuitively be linked to either the use of Minecraft or communication of science, as part of project evaluation for Science Hunters, we asked people attending public events through their own choice to tell us: (1) how often the child participating plays Minecraft; (2) whether the child participating or the adult accompanying them decided to attend the session; and (3) how interested that person is in science and in Minecraft, and which element most strongly influenced his or her decision to take part in the session. All data were gathered using self-completed paper questionnaires handed to accompanying adults at the following public events (see Table 1): Lancaster University Community Day (2017); Lancashire Science Festival (2017); Science Hunters at Lakeland Wildlife Oasis (2018); and Geronimo Children's Festival (2018). Adults were asked to complete the questionnaires rather than children, so that data collection did not interfere with children's participation in the activity, and to minimize bias towards opinions of children with higher literacy levels. Children as well as adults had to consent to the data collection, as they would be asked for their input in cases where they had chosen to come to the session themselves. Although this information was collected for evaluation rather than research purposes, data collection nevertheless conformed to the standards of the British Educational Research Association Ethical Guidelines for Educational Research (BERA, 2014) and this secondary analysis of the data has been approved by the Lancaster University Faculty of Science and Technology Ethics Team.

Along with basic demographic information, respondents reported whether adults or children made the decision to attend via tick boxes, in order to ensure that the attitudes of the person most influential in choosing the activity were captured. Likert and semantic differential scales were used to indicate: (1) frequency of children's Minecraft play; (2) interest in science; (3) interest in Minecraft; and (4) balance between science and Minecraft as the factor behind their decision to attend. These scales ranged from 1 (never/very uninterested/science, as appropriate) to 5 (frequently/very interested/Minecraft, as appropriate).

At Geronimo Children's Festival, a three-day event, different project sessions were delivered on each day. Responses were collected during one of these days, on which 217 children attended. At other events, all attendees were offered the opportunity to give feedback.

Where responses indicated that the child was the decision maker, and therefore the provider of information on interests and play frequency, these quantitative indicators were compared with children's school year group - covering preschool (age 4 years and younger) to Year 13 (age 18 years) - and whether they were male or female. The resulting data were not normally distributed, and therefore nonparametric statistical tests (see Box 1) were used to investigate the relationships between participants' interests and reasons for choosing the activity. Spearman's correlations (giving correlation coefficient $r_{s}$ ) were used to explore whether there were significant relationships between these factors; for example, whether there is a correlation between interest in science and interest in Minecraft, or between interest in science and reason for coming to the activity. Mann-Whitney $U$ tests were used to check whether there were significant differences between respondent groups; for example, whether children were more interested in science than adults. The level of significance for these tests was set to 0.05 , and therefore tests returning a p-value lower than this were considered to have found a statistically significant relationship (that is, there is more than a 95 per cent chance that the relationship actually exists). 


\section{Box 1: Notes on statistics used}

Normal distribution of data: Data are described as 'normally distributed' when they are centred around a mean (average value) and decrease equally towards the lower and higher ends of the range of values present. An example of this would be information about the heights of people in a population. Most people will be close to average height. The numbers of people who are shorter and taller than average height will be approximately equal, and only a small number of people will be either very short or very tall. Some statistical tests ('parametric tests') assume that data are normally distributed in order to work; however, this is not always the case. For example, if a large group of people were asked to choose a number between 1 and 100 , there could be peaks of results at several points along the scale, including at either end.

Non-parametric tests: These are statistical tests which do not assume that data are normally distributed. Statistical software can be used to confirm whether or not data are normally distributed, and therefore which statistical test is most appropriate to use when analysing the data set.

Correlation coefficients: A correlation coefficient has a value between -1 and 1 , and tells you how strong the relationship is between two variables (for example, characteristics). A coefficient of -1 indicates a strong negative relationship, while a coefficient of 1 marks a strong positive relationship. A coefficient of 0 would indicate no relationship between the variables. For example, when looking at data about ages and heights of children, we would expect to see a positive correlation coefficient as we know that children's heights increase as their ages increase, and therefore we would expect a correlation coefficient closer to 1 than 0 .

p-values: A p-value is a 'calculated probability'. It is a value between 0 and 1 that tells you the probability that your results could have happened by chance. For example, if a correlation were found between hours spent in extra-curricular activities and exam results, the p-value would tell you whether or not this correlation was significant (should be accepted), and how likely it is that you could have obtained these results if there was no genuine correlation between extra-curricular hours and exam performance. Generally, 0.05 (5 per cent probability) is used as a threshold, and therefore a p-value of less than 0.05 indicates that a result is significant (less than 5 per cent probability that it happened by chance).

\section{Results}

\section{Age range of children attending public events}

Figure 6 demonstrates that the majority of children attending public events through choice are primary school aged (age 4-11 years), with a core audience in school Years 3 to 5 (age 7-10 years). These year groups sit within Key Stage 2 in the national curriculum in England (DfE, 2014). This information was gathered from participants in our sessions at Lancashire Science Festival (2017) and Lakeland Wildlife Oasis (2018), two public family-based events at which we obtained demographic data from a high proportion of attendees (82 per cent and 91 per cent respectively) using questionnaires. We also looked at age distributions when including information from other events at which we collected data from a smaller proportion of attendees (35 per cent of the total across 
all five events; see Figure 7); the core audience remains primary school aged, falling within Years 1 to 6 (Key Stages 1 and 2).

Figure 6: School year groups of 179 children attending Science Hunters public events at Lancashire Science Festival (2017) and Lakeland Wildlife Oasis (2018), at which demographic data were collected from a high proportion (84 per cent) of attending children

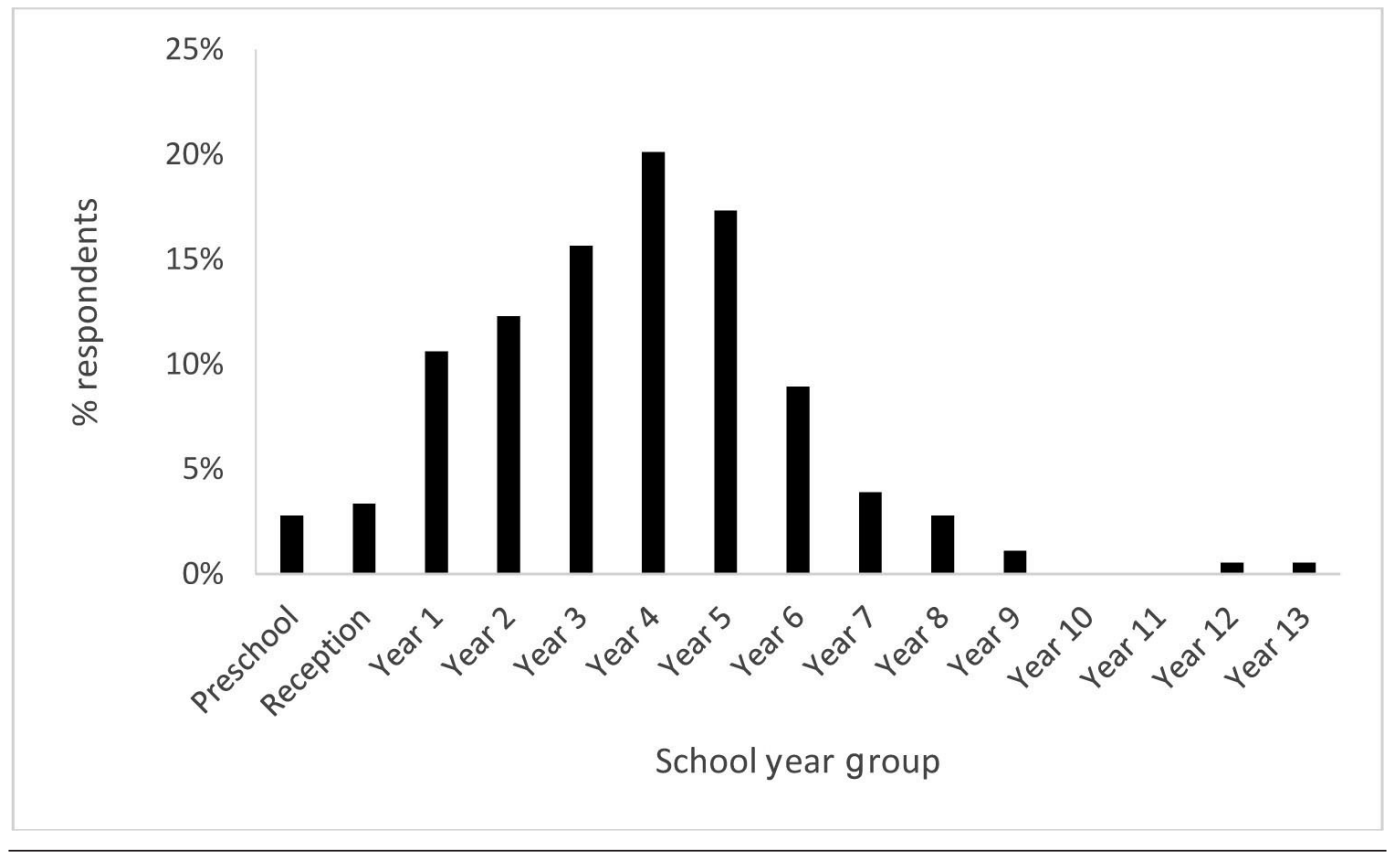

Figure 7: School year groups of 478 children attending Science Hunters public events at Lancaster University Community Day (2017), Lancashire Science Festival (2017), Lakeland Wildlife Oasis (2018), Geronimo Children's Festival (2018) and Lancashire Science Festival (2018), where demographic information was collected from a combined total of $\mathbf{3 5}$ per cent of attending children

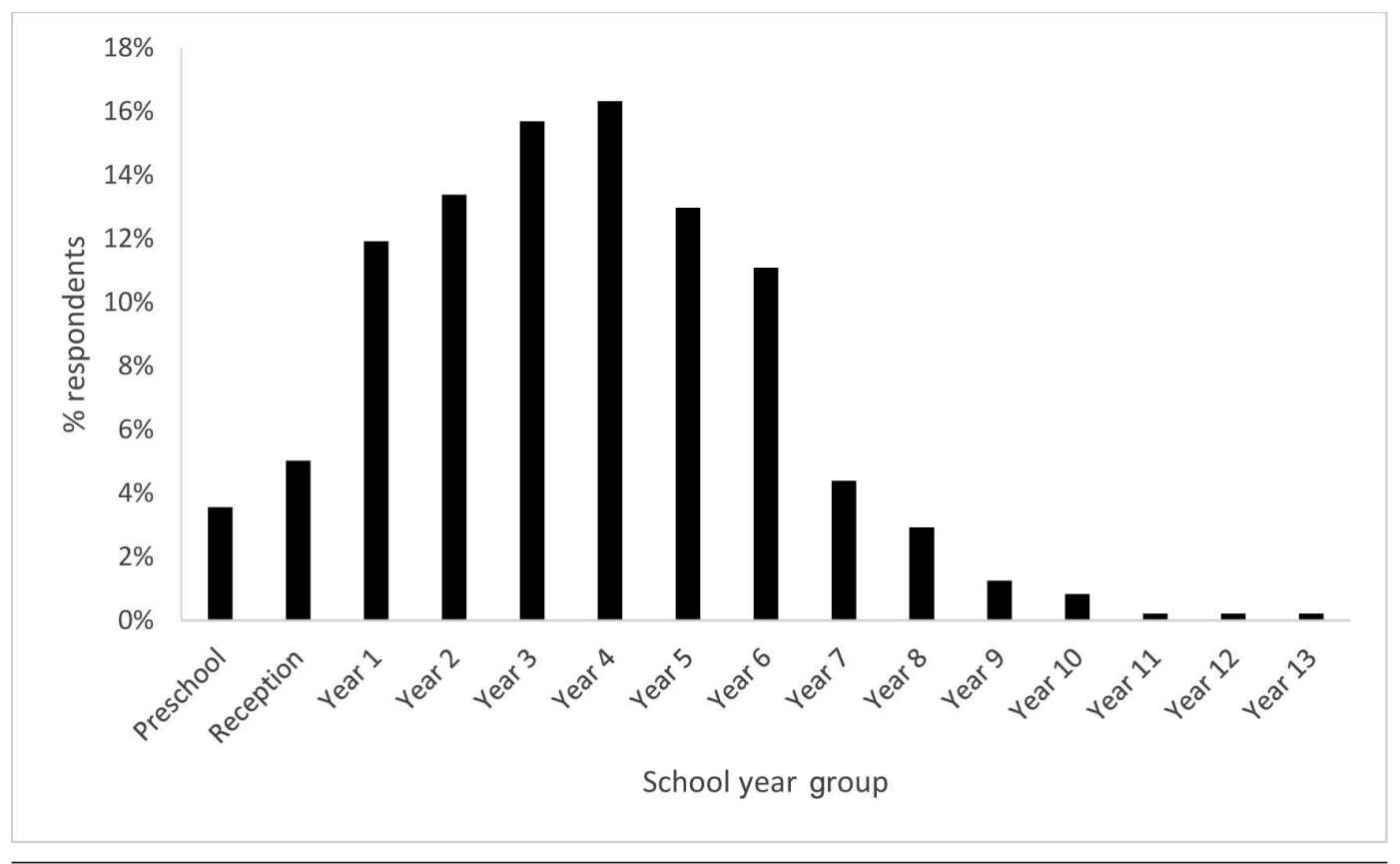




\section{General event feedback}

In total, 43 pieces of feedback containing 64 pieces of categorized content were collected using word wall feedback, and 371 smiley face feedback cards were returned. Feedback was highly positive, with 90 per cent of smiley face feedback cards giving a positive response. Only 0.3 per cent were negative. Most of the neutral feedback and one negative response came from sessions at Lancashire Science Festival (2018); feedback from the other two events was around 3 per cent more positive for both (see Table 2).

Feedback cards contained a further 271 instances of written feedback, containing 534 pieces of categorized content. Therefore, 314 comments containing 598 pieces of content were categorized in total (see Figure 8). Only comments relating to the Science Hunters activity itself, rather than the logistics of the main event, such as timings and set-up, were included. Figure 8 shows distribution of comments between categories, while Table 2 shows the feedback given using smiley faces on feedback cards at events in 2018.

Table 2: Feedback given in 2018 via cards $(n=371)$

\begin{tabular}{lccc}
\hline Event & $\begin{array}{c}\text { Positive/happy } \\
\text { (number (\%)) }\end{array}$ & $\begin{array}{c}\text { Neutral } \\
\text { (number (\%)) }\end{array}$ & $\begin{array}{c}\text { Negative/unhappy } \\
\text { (number (\%)) }\end{array}$ \\
\hline $\begin{array}{l}\text { Campus in the City } \\
\text { (2018) }\end{array}$ & $49(92.5)$ & $4(7.5)$ & $0(0)$ \\
$\begin{array}{l}\text { Geronimo Children's } \\
\text { Festival (2018) }\end{array}$ & $105(92.9)$ & $8(7.1)$ & $1(0.3)$ \\
$\begin{array}{l}\text { Lancashire Science } \\
\text { Festival (2018) }\end{array}$ & $178(87.3)$ & $25(12.3)$ & $1(0.3)$ \\
$\begin{array}{l}\text { Total/\% of overall } \\
\text { total }\end{array}$ & $332(89.5)$ & $37(10.0)$ & $2(0.5)$ \\
\hline
\end{tabular}

Figure 8: Distribution of comments between categories for feedback given via word walls and feedback cards

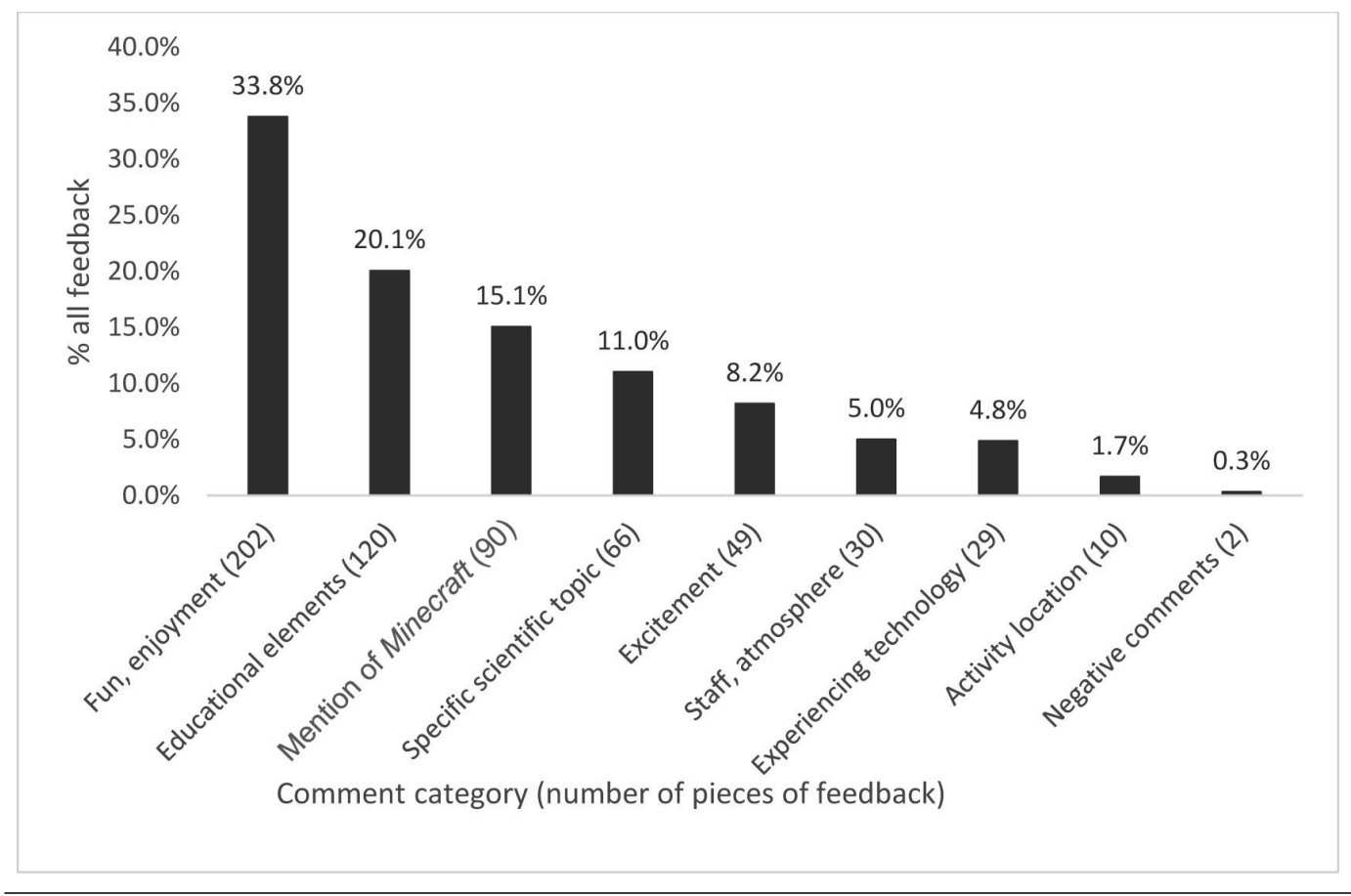




\section{Correlation of children's demographics and interests}

In total, 289 responses to the motivational questionnaire were collected, giving a response rate of 44.8 per cent. Of attending children, 213 (74.2 per cent) were reported as male and 74 (25.8 per cent) as female. The only significant relationship that was found between children's characteristics and interests in science and Minecraft was a moderate positive correlation $\left(r_{s}=0.340, p=<0.001\right)$ between school year group (age) and how frequently a child plays Minecraft; as children get older, their Minecraft play frequency tends to increase, although there were also some frequent players in the younger year groups, with some children playing regularly from Reception (age 4-5 years). For the children who responded, overall play frequency increases around Year 5 (age 9-10 years), then continues to increase to Year 9 (age 13-14 years), from where it remains high until a slight decline at Year 13.

\section{Interests in science, Minecraft and reasons for coming}

Of the 289 responses collected, 287 reported whether the child or the accompanying adult made the decision to come to the Science Hunters activity. In 178 cases (62.0 per cent), the child made this decision. Adults made the decision in 87 instances (30.3 per cent), and the decision was made jointly for a further 22 (7.7 per cent). Table 3 shows mean and modal values for interest in science, interest in Minecraft and reason for coming, for all attendees at all events, along with further breakdown for adults and children where a significant difference was found between these two groups. The distribution of reasons for coming is shown in Table 4.

Table 3: Mean and modal values for interest in science, interest in Minecraft and reason for coming, for all attendees at all events, along with further breakdown for adults and children where a significant difference was found between these two cohorts

\begin{tabular}{|c|c|c|c|}
\hline & Mean & Mode & $\begin{array}{l}\text { Significant } \\
\text { difference between } \\
\text { children and adults? } \\
\text { (Mann-Whitney U } \\
\text { test) }\end{array}$ \\
\hline $\begin{array}{l}\text { Interest in science } \\
(1=\text { very } \\
\text { uninterested, } 5=\text { very } \\
\text { interested })\end{array}$ & $4.39 \pm 0.04$ & 5 & No $(p>0.05)$ \\
\hline $\begin{array}{l}\text { Interest in Minecraft } \\
(1=\text { very } \\
\text { uninterested, } 5=\text { very } \\
\text { interested })\end{array}$ & $4.04 \pm 0.06$ & 5 & $\begin{array}{l}\text { Yes }(p<0.0001) \\
\text { Children: } \text { mean }= \\
4.37 \pm 0.07, \text { mode }=5 \\
\text { Adults: } \text { mean }=3.29 \\
\pm 0.11, \text { mode }=3\end{array}$ \\
\hline $\begin{array}{l}\text { Reason for coming } \\
(1=\text { science, } 5= \\
\text { Minecraft })\end{array}$ & $3.53 \pm 0.07$ & 3 & No $(p>0.05)$ \\
\hline
\end{tabular}


Table 4: Distribution of responses for driving factor behind choosing the Science Hunters activity from the programme of activities available (the balance between science and Minecraft was indicated on a Likert scale of 1 (science) to 5 (Minecraft))

\begin{tabular}{ccc}
\hline Reason & Scale & Responses (number (\%)) \\
\hline Science & 1 & $25(8.7)$ \\
& 2 & $27(9.4)$ \\
& 3 & $92(32.2)$ \\
Minecraft & 4 & $55(19.2)$ \\
\hline
\end{tabular}

A small majority of people said that science and Minecraft were equal (a score of 3 in Table 4) in influencing their decision to choose the activity; of those who indicated either science or Minecraft (scores other than 3), 18.2 per cent chose science and 49.7 per cent chose Minecraft. Interest in science in children, and interest in Minecraft in both children and adults, ranged from 1 to 5 (very uninterested to very interested). Interest in science in adults ranged from 2 to 5 (uninterested to very interested).

Statistically significant correlations were found between:

- interest in science and interest in Minecraft $\left(r_{s}=0.244, p<0.001\right.$; weak positive correlation)

- children's interest in Minecraft and the frequency of their play on Minecraft $\left(r_{s}=0.243, p<0.001\right.$; weak positive correlation)

- children's interest in Minecraft and Minecraft driving the decision to attend $\left(r_{s}=0.255, p<0.001\right.$; weak positive correlation).

\section{Comparison of data from science and non-science events}

When data collected from attendees at activities that were part of wider science events (Lancashire Science Festival 2017) and non-science events (Lancaster University Community Day 2017, Lakeland Wildlife Oasis 2018 and Geronimo Children's Festival 2018) were considered separately, there were no significant differences ( $p>0.05$ ) between interest in science or interest in Minecraft in participants across these two types of event. Adults were again less interested than children in Minecraft, with no significant difference in interest in science between children and adults.

There was no significant difference $(p>0.05)$ in reason for coming between attendees at science-based and non-science-based events. The mean overall 'reason for coming' score was slightly weighted towards Minecraft for both: $3.56 \pm 0.11$ ( $n=127)$ for non-science events and $3.51 \pm 0.10(n=159)$ for the science event, with no significant difference between responses from adults and children.

At the non-science events, the following statistically significant correlations were found:

- interest in science and science driving choice of activity $\left(r_{s}=0.209, p=0.018\right.$; weak positive correlation)

- interest in Minecraft and Minecraft driving choice of activity $\left(r_{s}=0.276, p=0.002\right.$; moderate positive correlation).

These relationships were not statistically significant for responses from the science event. Frequency of the child's play on Minecraft and reason for coming were also compared for the science event, as no significant correlation could be found between 
reason for coming and interest in science or interest in Minecraft for this event. For all attendees $(n=158)$, there was a significant weak positive relationship $\left(r_{s}=0.171\right.$, $p<0.031)$; for children $(n=80)$, this relationship was slightly stronger $\left(r_{s}=0.241\right.$, $p<0.031)$ and for adults $(n=64)$, there was no significant relationship.

\section{Discussion}

\section{Ages of children attending Science Hunters activities through choice}

Based on data collected at public family events, the core body of children attending Science Hunters activities by choice are of primary school age, that is, age 11 years or younger. Given the onset of decline in interest in science around age 10 (Murphy and Beggs, 2005), children of primary school age are ideal as beneficiaries of outreach and engagement with science and research, particularly given the positive influence on this decline of practical, investigative activities (Murphy et al., 2004); this evaluation indicates that Science Hunters activities naturally appeal to this core group.

\section{General event feedback}

Results from general feedback are clearly positive, although slightly less so for Lancashire Science Festival (2018). It is unclear why activities were less well received here than at the other events; it could be that the physical set-up (fixed computers on lines of desks, compared with portable laptops around tables) was less appealing as an informal learning environment and took longer to navigate at the start of sessions, encroaching on activity time, or that the sessions were less enjoyable because Lancashire Science Festival took place on uncomfortably hot days in 2018. There was one negative (sad, red face) response with a comment; while this has been categorized as one of the two 'negative' pieces of feedback content as the smiley face response was negative, the comment was difficult to read and was contradictory. For example, it starts with 'It was OK' despite the negative response and says 'a little bit no fun it was fun'. Another comment of 'It was OK but I wish there was more learning to it' was left with a neutral (yellow face) response and contains the other piece of 'negative' content recorded. It is unclear why the respondent felt learning was lacking as they have not elaborated, and this is not consistent with other feedback, which strongly recognizes the educational and learning elements of the sessions.

At Geronimo Festival, the one negative response was given by a 6-year-old child, with no comment. This therefore makes it difficult to interpret; one learning point from this exercise was that, while colours for faces were used to aid interpretation and accessibility for children completing the cards, we were told that some children were more drawn to their preferred colours than the emotions expressed by the faces, needing adult assistance to complete them correctly. Others were unhappy at the point that they completed the cards, as they had been told that it was time to leave the activity, and again needed adult help to enable them to relate their feedback to how they found the activity itself. Therefore, the 'negative' comments left are difficult to interpret, and do not provide any insights into why the sessions at Lancashire Science Festival received slightly less positive feedback than those at other events. As these 'non-positive' comments made up a very small ( $<0.5$ per cent) proportion of all feedback analysed, it appears that most participants are receiving a positive experience by attending the activities.

Comments most commonly related to fun and enjoyment of the activity (34 per cent), the educational aspects (20 per cent) and Minecraft (15 per cent). Specific 
scientific elements were mentioned in 11 per cent of comments. This indicates that children are relating to both the scientific aspects of the activity and the use of Minecraft, and are aware that they are learning as they play. They are also having fun, which is important for creating positive associations with science and learning about science, and therefore for counteracting cultural biases that lead children to see science as 'not for them' (for example, Archer et al., 2013), and for efficacy of learning (Lepper and Cordova, 1992).

\section{Motivation information}

Feedback revealed that the majority of children attending (74 per cent) were boys; video gaming has been problematically stereotyped as a male domain (Shaw, 2010 and references therein), which may be influencing who attends activities involving computer games. There was, however, no significant difference in interest in science, interest in Minecraft or frequency of Minecraft play between boys and girls attending. The tendency of Minecraft play frequency to increase with age is not unexpected, as children become more able to complete complex tasks as they develop skills.

On average, people attending our activities had high interest in science, with no significant difference between children and adults. Average interest in Minecraft was also high, with children having high interest and adults having moderate interest.

The reason for choosing the Science Hunters activity out of all those on offer was consistently weighted slightly towards Minecraft, across all events. There was no correlation between interest in science or interest in Minecraft and the reason for choosing the activity at the science event, which could be explained by the fact that everybody present had already chosen to attend the main event because of the science on offer, and because there were other activities utilizing Minecraft available; some other factor, such as the specific science topics available or the timing of the activity within the day, may have had more influence, so that there was no strong preference towards either science or Minecraft. There was, however, a weak correlation between frequency of Minecraft play, which was also shown to correlate to interest in Minecraft, and Minecraft driving this choice.

At the non-science events, there was a weak correlation between interest in science and science driving the choice of activity, and a moderate correlation between interest in Minecraft and Minecraft driving the choice to attend. These outcomes suggest that: (1) Science Hunters activities are attracting both children and adults (who are choosing the activity for their children, and facilitating their attendance and participation) with a broad range of interests - while average interest in both science and Minecraft were high, there were some attendees who described their interest in one of these elements as low; and (2) that Minecraft is effective as a tool for drawing people to an activity, in which they can then be engaged with research topics. In addition to the existing use of Minecraft in a wide range of formal education and learning research settings, the scope of the Minecraft virtual environment is so wide that there are many and varied possibilities for using it to engage children with a range of research fields, both within and outside of science. This approach could be transferred to engagement with a multitude of topics, using Minecraft and a creative, supportive ethos to both attract and facilitate engagement.

\section{Conclusions}

Primary-school-aged children are a core audience for Science Hunters activities, and while these are mainly attended by boys, there is no difference between interest in 
science or interest in Minecraft between the boys and girls who take part. Feedback is highly positive, with fun, enjoyment and the educational aspect of the activities having the most impact on attendees, indicating effective engagement. As well as being an effective engagement tool used within our approach during the sessions, at all events there are indications that Minecraft is the most influential feature of the activity when people are choosing which session to attend from a programme of activities, with around three times as many people choosing to attend due to Minecraft being involved rather than because science is featured. Therefore, the Science Hunters approach to using Minecraft to engage children with scientific research is effective both at attracting participants and having a positive impact on them. It is important to note that it is not only the use of Minecraft that makes the Science Hunters approach effective. The inclusive nature of the sessions (all ages and abilities are welcomed, and adjustments are made for additional needs with tolerance for all needs emphasized) and the pedagogical strategy of combining creative, child-driven gameplay with practical anchoring in an informal manner are fundamental to the project's success (Hobbs et al., 2019), and are learning points to be considered alongside the findings presented here. As Minecraft is an open-ended game, this approach is transferable to engagement with other research areas, both within and outside the scientific arena.

\section{Acknowledgements}

Science Hunters is funded by Lancaster University. We would like to thank our student volunteers and supporting staff from Lancaster University, the venues that have supported our sessions, and all of the adults and children who have attended our events and made them a success; particularly those who have responded to our requests for feedback and enabled us to conduct our evaluation.

\section{Notes on the contributors}

Laura Hobbs has a PhD in environmental science and an MSci in geology. With a research background in both volcanology and science communication, she coordinates the Science Hunters project at Lancaster University. She also runs Science from the Start, specializing in science communication for underserved audiences, and is a Research Fellow in Science Communication at the University of the West of England, Bristol.

Carly Stevens has a PhD in plant ecology and is a senior lecturer in ecology and Director of Postgraduate Research Students at Lancaster Environment Centre. She initiated the Science Hunters project in 2014 after realizing that computer games had great potential to enthuse and inspire students who were less engaged with their education. Her own research is into how global change impacts on plants and soils.

Jackie Hartley has a PhD in animal behaviour and a BSc in zoology. After completing her PGCE in secondary science teaching, she taught for over 15 years in school and college. She is now a Science Hunters project assistant at Lancaster University, developing and delivering Science Hunters sessions, and works as an education officer in the energy industry.

Mark Ashby has a PhD in ecology and a BSc in environmental conservation. He is studying the decline in arctic alpine plant species within the limestone grasslands of upper Teesdale, and soft rush expansion with upland grasslands at Lancaster University. 
Isobel Lea is currently studying for a BSc in psychology at Lancaster University. She is interested in how the psychology of the mind can be applied to every aspect of life, and hopes one day to provide insightful research in the field.

Lauren Bowden has a BSc in psychology from Lancaster University, and began a doctorate in educational psychology at Newcastle University in 2018. From 2016 to 2018, Lauren had roles within school settings, as a special educational needs learning support assistant and as an assistant educational psychologist. Her interests lie in the inclusion of children in educational settings and their engagement with learning.

Jordan Bibby has a BSc in psychology from Lancaster University. After studying, he experienced a year as a support worker in a looked after children's home, and then completed a master's degree at the University of Edinburgh to become an applied psychologist within the NHS child and adolescent mental health service. Jordan is interested in early intervention for mental health, mindfulness, CBT and clinical psychology, and is currently affiliated to NHS Lanarkshire.

Benjamin Jackson has a PhD in environmental science from Lancaster University. He has a background in river catchment management, but is also interested in outreach and pedagogy. He is currently working at the University of Exeter as an Impact Fellow on projects related to water management.

Rhian McLaughlin has a PhD in history from the University of York, and an MA in medieval history from Durham University. She has worked in education and engagement in York, Tokyo and Lancaster, including coordinating the Campus in the City outreach programme at Lancaster University, and now works for the Government Communication Service.

Thomas Burke is a graduate researcher at Lancaster University, exploring the use of computers and technology to investigate and communicate agri-environmental issues. Prior to this, he completed a master's degree in earth and environmental science, and assisted in the promotion and dissemination of coastal research, both also at Lancaster University.

\section{References}

Amory, A., Naicker, K., Vincent, J. and Adams, C. (1999) 'The use of computer games as an educational tool: Identification of appropriate game types and game elements'. British Journal of Educational Technology, 30 (4), 311-21.

Archer, L., DeWitt, J., Osborne, J., Dillon, J., Willis, B. and Wong, B. (2012) 'Science aspirations, capital, and family habitus: How families shape children's engagement and identification with science'. American Educational Research Journal, 49 (5), 881-908.

Archer, L., Osborne, J., DeWitt, J., Dillon, J., Wong, B. and Willis, B. (2013) ASPIRES: Young people's science and career aspirations, age 10-14. London: King's College London. Online. https://tinyurl.com/yyml6wda (accessed 3 June 2019).

Barab, S., Pettyjohn, P., Gresalfi, M., Volk, C. and Solomou, M. (2012) 'Game-based curriculum and transformational play: Designing to meaningfully positioning person, content, and context'. Computers and Education, 58 (1), 518-33.

BERA (British Educational Research Association) (2014) Ethical Guidelines for Educational Research. Online. https://tinyurl.com/ldk4578 (accessed 3 June 2019).

Betz, J.A. (1995) 'Computer games: Increase learning in an interactive multidisciplinary environment'. Journal of Educational Technology Systems, 24 (2), 195-205.

Brooks, J.G. and Brooks, M.G. (2001) In Search of Understanding: The case for constructivist classrooms. Rev. ed. Upper Saddle River, NJ: Merrill Prentice Hall.

Castell, S., Charlton, A., Clemence, M., Pettigrew, N., Pope, S., Quigley, A., Shah, J.N. and Silman, T. (2014) Public Attitudes to Science 2014. London: Ipsos MORI Social Research Institute. 
Cognition and Technology Group at Vanderbilt (1990) 'Anchored instruction and its relationship to situated cognition'. Educational Researcher, 19 (6), 2-10.

Czerski, H. (2016) Storm in a Teacup: The physics of everyday life. London: Bantam Press.

DfE (Department for Education) (2014) 'National curriculum'. Online. https://tinyurl.com/pt2jc2b (accessed 3 June 2019).

Harlen, W. and Qualter, A. (2018) The Teaching of Science in Primary Schools. 7th ed. London: Routledge.

Hobbs, L., Stevens, C. and Hartley, J. (2018a) 'Environmental education and engagement using a construction play computer game'. Roots Education Review, 15 (1), 20-3.

Hobbs, L., Stevens, C. and Hartley, J. (2018b) 'Digging deep into geosciences with Minecraft'. Eos, 99 (11), 24-9.

Hobbs, L., Stevens, C., Hartley, J. and Hartley, C. (2019) 'Science hunters: An inclusive approach to engaging with science through Minecraft'. Journal of Science Communication, 18 (2), Article N01, 1-12. Online. https://tinyurl.com/ybcbb5hb (accessed 3 June 2019).

House of Commons Science and Technology Committee (2017) Science Communication and Engagement: Eleventh report of Session 2016-17. London: House of Commons. Online. https://tinyurl.com/yyeggbvl (accessed 3 June 2019).

Jayakanthan, R. (2002) 'Application of computer games in the field of education'. Electronic Library, 20 (2), 98-102.

Kerr, K. and Murphy, C. (2012) 'Children's attitudes to primary science'. In Fraser, B.J., Tobin, K.G. and McRobbie, C.J. (eds) Second International Handbook of Science Education (Springer International Handbooks of Education 24). Dordrecht: Springer, 627-50.

Lancaster University (n.d.) 'Litcraft'. Online. https://tinyurl.com/yy36ya5f (accessed 3 June 2019).

Lancaster University (2019) 'Widening participation - frequently asked questions'. Online. https://tinyurl.com/y6a9dx7s (accessed 3 June 2019).

Lane, H.C. and Yi, S. (2017) 'Playing with virtual blocks: Minecraft as a learning environment for practice and research'. In Blumberg, F.C. and Brooks, P.J. (eds) Cognitive Development in Digital Contexts. London: Academic Press, 145-66.

Lepper, M.R. and Cordova, D.I. (1992) 'A desire to be taught: Instructional consequences of intrinsic motivation'. Motivation and Emotion, 16 (3), 187-208.

Loyens, S.M.M. and Gijbels, D. (2008) 'Understanding the effects of constructivist learning environments: Introducing a multi-directional approach'. Instructional Science, 36 (5-6), 351-7.

Mojang (2019a) 'Molcraft'. Online. https://education.minecraft.net/worlds/molcraft/ (accessed 8 August 2019).

Mojang (2019b) 'Minecraft: Education edition'. Online. https://education.minecraft.net/ (accessed 3 June 2019).

Murphy, C. and Beggs, J. (2005) Primary Science in the UK: A scoping study: Final report to the Wellcome Trust. London: Wellcome Trust.

Murphy, C., Beggs, J., Carlisle, K. and Greenwood, J. (2004) 'Students as "catalysts" in the classroom: The impact of co-teaching between science student teachers and primary classroom teachers on children's enjoyment and learning of science'. International Journal of Science Education, 26 (8), 1023-35.

Nebel, S., Schneider, S. and Rey, G.D. (2016) 'Mining learning and crafting scientific experiments: A literature review on the use of Minecraft in education and research'. Educational Technology and Society, 19 (2), 355-66.

Papert, S. and Harel, I. (1991) 'Situating constructionism'. In Harel, I. and Papert, S. (eds) Constructionism: Research reports and essays, 1985-1990. Norwood, NJ: Ablex, 1-11.

Rovai, A.P. (2004) 'A constructivist approach to online college learning'. The Internet and Higher Education, 7 (2), 79-93.

Shaw, A. (2010) 'What is video game culture? Cultural studies and game studies'. Games and Culture, 5 (4), 403-24.

Short, D. (2012) 'Teaching scientific concepts using a virtual world - Minecraft'. Teaching Science, 58 (3), 55-8. 